2020-01

\title{
A measure to assess the workplace wellbeing of psychological practitioners
}

Summers, EMA

http://hdl.handle.net/10026.1/15634

10.1002/cpp.2401

Clinical Psychology \& Psychotherapy

Wiley

All content in PEARL is protected by copyright law. Author manuscripts are made available in accordance with publisher policies. Please cite only the published version using the details provided on the item record or document. In the absence of an open licence (e.g. Creative Commons), permissions for further reuse of content should be sought from the publisher or author. 


\title{
Notes: MCLellan (2018) replaces Phase 1 throughout.
}

\section{Table 1 insert left in introduction}

\begin{abstract}
The wellbeing of psychological practitioners is a key factor in the effective delivery of psychological therapies and the effectiveness of mental health services. Despite this, there are no measures of wellbeing for this professional group. The 26-item Psychological Practitioner Workplace Wellbeing Measure (PPWWM) measures psychological wellbeing for psychological practitioners and informed by a qualitative study. Items were generated and then verified by groups of practitioners using sorting tasks. The items reflect a broad range of issues relevant to the workplace wellbeing of psychological practitioners.

The PPWWM was validated with a sample of 400 psychological practitioners recruited through professional networks. Internal consistency $(\alpha=.92)$ and test-retest reliability $(r=.94)$ were high. Construct validity was indicated by positive correlations with the Health and Safety Executive Management Standards Indicator Tool and Satisfaction with Life Scale (SWLS) and negative correlation with the General Health Questionnaire (GHQ12). Exploratory factor analysis produced six factors, explaining $61.2 \%$ of the variance: professional and organisational; support and flexibility; professional role; physical environment; clinical supervision; external personal. PPWWM scores were not significantly associated with a range of demographic variables (gender, health/disability, profession, type of organisation), but it did correlate significantly and negatively with age.
\end{abstract}

The PPWWM has potential application as a brief measure, suitable for large-scale surveys that specifically measures workplace well-being in psychological practitioners. 
Future research could include cross validation with new samples and validation with subgroups of psychological practitioners.

\section{Key Practitioner Message}

- The Psychological Practitioner Workplace Wellbeing Measure (PPWWM) is a brief measure specifically measuring factors relevant to the workplace wellbeing of psychological practitioners.

- The PPWWM is acceptable to psychological practitioners, generating only $14 \%$ incomplete responses even when delivered by internet without personal contact.

- The PPWWM has excellent internal consistency and temporal stability (reliability), good construct validity and a coherent factor structure. 


\section{Introduction}

Interest in health practitioner workplace wellbeing has been stimulated by reports and guidelines (The National Institute for Health and Clinical Excellence (NICE), 2009; Stevens, 2014). These reports highlight the association between practitioner wellbeing and key organisational outcomes such as improved patient satisfaction and outcomes, better staff retention and lower rates of sickness absence and burnout (Boorman, 2009). In the UK National Health Service (NHS) staff wellbeing is now recognised as an important factor in attracting and retaining skilled staff (Stevens, 2014). Concern about staff wellbeing in health services has been further stimulated by the finding that employee wellbeing in health and social care organisations is poor (Johnson et al., 2005, Maslach \& Leiter, 2016). This may be linked to recent cost-savings and performance targets (Hall et al., 2016) which engender low staffing levels and heavy workloads (Stevens, 2014). The wellbeing of psychological practitioners is an area of particular concern (Rupert \& Morgan, 2005; Dattilio, 2015; Dosanjh \& Bhutani, 2017), but there is currently no workplace wellbeing measure for this group.

Occupational wellbeing encompasses mental and physical health alongside job satisfaction. It is considered to have two facets (Maben et al., 2012). The positive aspects encompass good experience within the workplace, job satisfaction and enjoyable aspects of work (Warr et al., 2011). The negative aspects include stress, anxiety, 'burnout' and exhaustion in the workplace (Fisher, 2010). Two other models of workplace wellbeing echo this dual-aspect model, extending it to consider antecedents and outcomes. The 'Job Demands and Resources Model' (Bakker \& Demerouti, 2007) categorises job attributes into 'resources' and 'demands'. Resources such as support and supervision facilitate workplace wellbeing, while demands such as work overload, role conflict and job complexity engender reduced wellbeing and increased burnout (Crawford, LePine \& Rich, 2010). The 
'Conservation of Resources' model (Hobfoll \& Shirom, 2001) offers a similar account; resources maintain a sense of positive wellbeing whereas a perceived threat to resources engenders distress, job dissatisfaction and reduced occupational wellbeing. An implication of the dual-aspect model is that assessing workplace wellbeing requires attention to both positive and negative facets and cannot be accomplished by proxy measurement of just one aspect such as burnout (c.f. Hall et al., 2016). See Figure 1 for a summary of the dual aspect model of workplace wellbeing together with the relevant antecedents and outcomes of each aspect.

[Insert Figure 1 about here]

\section{Psychological Practitioner Wellbeing}

The term 'psychological practitioner' includes any professionally qualified practitioner working in a psychological/psychotherapeutic role. The high emotional demands of psychotherapeutic work have been extensively documented (e.g. D'Souza, Egan \& Rees, 2011; Farber, 1983; Westwood, Morison, Allt \& Holmes, 2017). Psychological practitioners are exposed to significant vicarious distress and may face limited resources and excessive demands (Rupert \& Morgan, 2005). They may experience anxiety, depression, occupational stress, vicarious traumatisation, compassion fatigue and ultimately burnout (Dattilio, 2015). Burnout itself has been defined as a form of chronic psychological stress characterised by three dimensions; emotional exhaustion, depersonalisation of patients and feelings of a lack of personal accomplishment (Maslach, Jackson \& Leiter, 1996; Maslach \& Jackson, 1981).

Psychological practitioners are expected to deliver psychotherapy which is intimate, confidential and involves a non-reciprocal therapeutic relationship. In addition, they often have to manage significant risks (e.g. client self-harm) whilst working in isolation with low 
control over their workload and high demands on their time (Smith and Moss, 2009). Using negative outcomes such as stress, distress, burnout and depression as proxy indices for wellbeing, it has been shown that high targets and caseloads, low control over work, younger age and less years of experience were associated with reduced wellbeing in psychological practitioners (Cushway \& Tyler, 1994; Di Benedetto \& Swadling, 2014; D’Souza et al., 2011; Lasalvia, et al., 2009; Rupert \& Kent, 2007; Steel et al., 2015). However, these studies were limited by a focus on the negative aspects of wellbeing which does not capture the important positive aspects of the construct. Using a broader, unvalidated measure of psychological wellbeing, based upon the European Social Survey (New Economics Foundation, 2009), Dosanjh \& Bhutani (2017) found that $48 \%$ of practitioners had recently felt depressed, $46 \%$ had recently felt like a failure and $92 \%$ found their job stressful at least some of the time. However, these results have yet to be supported using a validated instrument.

\section{Assessment of Workplace Wellbeing in Psychological Practitioners}

Given the importance of psychological practitioner wellbeing for outcomes, it is vital that wellbeing can be assessed with a dependable, validated measure that specifically measures its positive and negative aspects in this professional group. Currently, there is wide variation in measures of general wellbeing (Linton, Dieppe \& Medina-Lara, 2016; Dimotakis, Scott \& Koopman, 2011). There exist only a few validated workplace wellbeing measures and these focus on either stress at work (Health and Safety Executive--HSE, 2004) or 'quality of work life' (Eaton, Mohr, Hodgson \& McPhaul, 2018; Van Laar, et al., 2007). However, these measures have limitations in that they focus on either the positive or the negative aspects of workplace wellbeing and none of them are specific to psychological practitioners. 
A qualitative study of wellbeing in psychology practitioners (McLellan, 2018), identified 14 salient constructs, categorised into four key areas (see Table 1). As predicted by the dual-aspect model, some constructs had positive and negative poles (positive and negative work aspects, hopefulness/hopelessness) while others referenced positive experiences (personal support versus lack of support, role clarity versus lack of clarity). This study highlighted the need for a psychology practitioner-specific measure of workplace wellbeing through identification of several influential dimensions that are absent from the HSE instrument (HSEMS -IT; HSE, 2004). The relevant factors missing form previous scales include:

- clinical supervision which is a part of practice standards for psychological practitioners;

- organisational factors (culture and climate) to which psychological practitioners may be particularly susceptible;

- physical environment because unfortunately some mental health service accommodation is unsuitable for confidential therapy work or is in poor repair;

- $\quad$ support from outside work provided by family and friends.

\title{
Insert Table 1 about here
}

\begin{abstract}
Aims
This study aimed to develop and validate a psychological practitioner workplace wellbeing measure (PPWWM). Items were based on the themes of a qualitative study (McLellan, 2018). Exploratory factor analysis factors were expected to map onto the themes identified by McLellan (2018) following their modification through the item development process (see below). Construct validity was assessed through a positive correlation with the
\end{abstract}


Health and Safety Executive Management Standards Indicator Tool (HSEMS-IT) (HSE, 2004), the Satisfaction with Life Scale (SWLS) (Diener, Emmons, Larsen \& Griffin, 1985) and a negative correlation with the General Health Questionnaire (GHQ-12) (Goldberg, 1992). The study also evaluated internal consistency as indexed by Cronbach's $\alpha$ and itemtotal correlations, and test-retest stability over a 14-day interval.

\section{Method}

\section{Ethics and Data Management}

Ethical approval was from the University ethics committee. Web-based survey software, Qualtrics ${ }^{\circledR}$, was used for data collection. No identifiable information was recorded except participant email addresses in the reliability sample. These were deleted once the participant had completed their involvement. Only anonymised data were stored.

\section{Procedure}

Item development was initially based on the qualitative work of McLellan (2018) by generating items to illustrate each of the 14 constructs identified in that study. Subsequently, the five-stage initial measure development process was guided by the work of DeVellis (2017). Participants were recruited from local psychological practitioners and professional networks. Inclusion criteria were being employed within an organisation as a qualified psychological practitioner (clinical, counselling, health or forensic psychologist, high intensity therapist, cognitive behaviour therapist, psychological wellbeing practitioner, counsellor, psychoanalyst, psychotherapist, family therapist and arts therapist). Individuals 
working solely in individual private practice (since organisational aspects would not apply), or those who were not professionally qualified, were not eligible to participate.

\section{Stage 1: Item Development}

Items were based on the 14 psychological practitioner wellbeing constructs (Table 1) identified in (McLellan, 2018). However, relevant literature (e.g. NICE, 2009; O’Donnell et al., 2014; Stevens, 2014) and previously validated measures (e.g. Van Laar, Edwards, \& Easton, 2007) were also consulted. McLellan (2018) identified 'personal support from family and friends' as important to workplace wellbeing. Although not a workplace factor, a review of the qualitative results revealed its relevance to workplace wellbeing and it was retained. An initial pool of 87 items, phrased as declarative statements to elicit unambiguous responses using a five-point Likert scale to assess agreement with the item. Four to nine items were generated across the 14 themes based on the complexity of the construct.

\section{Stage 2: Item Review}

The authors invited local psychological practitioners to participate in the item review (12 clinical psychologists and one cognitive behaviour therapist). A focus group was conducted with five clinical psychologists (38.5\% response rate). All were employed within the NHS. Due to small number of participants in the focus group, a further review of items was completed via a web-based survey. Individuals who were unable to attend the focus group ( $\mathrm{n}=8)$ and two members of a professional network were invited by email. Four clinical psychologists completed an email survey. All participants were asked to review the 87 items, commenting on relevance of each item to its construct, clarity, wording and ambiguity. Items were added, adapted or removed based on comments. Negatively and positively keyed items were introduced to reduce acquiescence response bias (approximately $70 \%$ positively 
worded). Participants deemed there was the need for an additional construct, 'organisational engagement' (inclusion in, and belonging to, the organisation and agreement with organisational objectives). The pool of items was refined to contain 60 items: four items relating to each of the 15 constructs.

\section{Stage 3: Construct Review}

A web-based Qualtrics ${ }^{\circledR}$ survey was distributed to psychological professional networks and mailing lists to cross-check items with the 15 constructs. Item order was randomised, and participants were required to select a single construct, from the list of 15 constructs, which they deemed most corresponded with each item. It is unknown how many psychological practitioners received the invitation. Twenty-six participants completed the survey. They were employed in a range of specialities. Fifty-two of the 60 items were most frequently matched with the intended construct. Four items intended to correspond with the 'professional line-management' construct were most frequently matched with the 'linemanagement support' construct. Therefore, these four items were amalgamated with the 'line-management support' construct and the four items with the highest frequency agreement in this new construct (of the eight) were selected. The four items associated with the 'pressure' construct were frequently allocated to other constructs; the 'pressure' construct being selected by fewer than $50 \%$ of the participants for each relevant item. Consequently, these items and the 'pressure' construct were removed. Fifty-two items, relating to the remaining 13 constructs, were retained (four items per construct). The final constructs are set out in Table 1 alongside the original 14 constructs from McLellan (2018) and their domains.

\section{Stage 4: Ranking of Item Relevance for Inclusion}


A web-based Qualtrics ${ }^{\circledR}$ survey contained a list of the 13 constructs with their four associated items. Participants rated the four items of each construct from 1 to 4 in order of importance/ relevance/ appropriateness as an exemplar of the construct. Recruitment was as for Stage 3. It is unknown how many psychological practitioners received the invitation, but 39 participants from a range of specialties completed the survey: clinical psychologist $(n=21)$; counselling psychologist $(n=4)$; high intensity therapist $(n=8)$; counsellor $(n=3)$; and psychological wellbeing practitioner $(n=3)$. The totals of the raters' scores for each of the four items under each of the 13 constructs were used to select the two items with the highest scores for inclusion in the final scale.

\section{Stage 5: Measure Review}

The order of items was randomised and a draft PPWWM survey was developed. Five individuals participated in this review process: clinical psychologist $(n=4)$; and psychotherapist $(n=1)$. Participants were employed in a range of specialties. No changes to the PPWWM were proposed. The PPWWM was predicted to take approximately five minutes to complete. The final measure contained 26 items, based on the 13 constructs of psychological practitioner workplace wellbeing: 2 items per construct. There were 21 positively keyed and 5 negatively keyed items, all use a 5-point Likert scale ranging from 1 (strongly disagree) to 5 (strongly agree), giving a minimum score of 26 and a maximum score of 130. Low scores indicate poor workplace wellbeing, while high scores indicate high workplace wellbeing.

\section{Psychometric Analysis of the PPWWM}

\section{Sample Size}


There is no established convention for determining sample size for the development of questionnaire evaluation measures. However, some hypotheses utilised correlations. G*Power software (Faul, Erdfelder, Lang \& Buchner, 2007) estimated a minimum sample size of 153 participants to detect a small correlation of .2 , at a power of .8 with alpha at .05 . For the factor analysis a ratio of 5 to 10 participants per item is recommended (Tinsley and Tinsley, 1987). Since the PPWWM has 26 items, 130-260 participants would suffice.

\section{Recruitment}

Participants were recruited from psychological practitioner mailing lists, professional organisations and networks and a closed social media group for clinical psychologists. Individuals were requested to share the invitation (a 'snowball' sample). Response rate is unable to be determined in such samples. The inclusion criterion was those able to communicate in English and currently employed in a UK health/social care organisation as a qualified psychological practitioner. Working solely in individual private practice was an exclusion criterion, given that these practitioners generally do not work in an organizational context and do not encounter the demands/resources conceptualized in the model. Not having a professional role or qualification was also an exclusion criterion.

\section{Measures}

A web-based Qualtrics ${ }^{\circledR}$ survey was created with the PPWWM, a demographic survey, the HSEMS-IT (HSE, 2004), Satisfaction with Life Scale (SWLS) (Diener et al., 1985) and the 12-item General Health Questionnaire (GHQ-12) (Goldberg, 1992). The

questionnaire was set up to require a response to all questions. Participants were all asked if they were willing to complete the survey a second time. Those who assented $(n=279)$ were 
sent the PPWWM seven days after first completion (Time 1). The second survey (Time 2) was completed 7 - 14 days after the first administration.

\section{Demographic Survey}

The demographic questionnaire collected participants' profession, type of contract, years since professional qualification, years worked since qualification, contracted hours, type of organisation, pay scale, gender, illness, disability and age.

\section{Health and Safety Executive Management Standards Indicator Tool (HSE, 2004)}

The UK Health and Safety Executive Management Standards HSEMS-IT (HSE, 2004) measures employees' exposure to work-related stress. It has 35 questions and six factors/subscales that have been identified by factor analysis: demands; control; managerial support; peer support; relationships; role; and change (Cousins et al., 2004; Edwards, Webster, Van Laar and Easton, 2008). It uses a seven-point self-report Likert scale from 1 (never) to 7 (always). Cronbach's $\alpha$ for the HSEMS-IT was 92 (Edwards, Webster, Van Laar \& Easton (2008), indicating high internal consistency (DeVellis, 2017). Cronbach's $\alpha$ of the seven subscales range from .89 to .78 (Cousins et al., 2004: Edwards et al., 2008). The testretest reliability has not been evaluated. The HSEMS-IT has been used in a range of professional settings demonstrating good construct validity with respect to job satisfaction and job-related anxiety and depression (Kerr, McHugh \& McCory, 2009).

\section{Satisfaction with Life Scale (Diener et al., 1985)}

The SWLS is a five-item self-report measure assessing global evaluation of life satisfaction according to personal criteria. It uses a seven-point Likert scale ranging from 1 (strongly disagree) to 7 (strongly agree). The SWLS has been widely used, including 
healthcare settings (Oates, Jones \& Drey, 2017). The Cronbach's $\alpha$ coefficient was .85 (Pavot, Diener, Colvin \& Sandvik, 1991) and .87 (Diener et al., 1985). The two-month testretest reliability was .82 (Diener et al., 1985) and one-month was .84 (Pavot et al., 1991). The SWLS has a single factor solution (Diener et al., 1985) and good construct validity with convergent and discriminant measures (Pavot \& Diener, 2008); it has strong negative associations with depression and negative affect (Larsen, Diener \& Emmons, 1985).

\section{General Health Questionnaire (Goldberg, 1992)}

The GHQ-12 is a self-report, 12-item scale (Goldberg, 1992) for non-psychotic mental health issues. It is used worldwide (Werneke, Goldberg, Yalcin \& Ustun, 2000) and was validated in clinical and non-clinical populations (e.g. Ruiz, García-Beltrán \& SuárezFalcón, 2017) and healthcare professional samples (Hardy, Shapiro, Haynes \& Rick, 1999). The scale assesses experience of a particular symptom or behaviour over the 'last few weeks', using a four-point Likert scale: less than usual, no more than usual, rather more than usual, or much more than usual. Higher scores indicate poorer mental health. The four-point Likert scale version (items scored from 0 to 3; total scores from 0 to 36) was used since it produces a more normal distribution than other scoring methods (Hardy et al., 1999). Cronbach's $\alpha$ was .90 (Hankins, 2008). Using this scoring method test-retest reliability values were .72 (Picardi, Abeni \& Paquini, 2001) and .82 (Piccinelli, Bisoffi, Bon, Cunico \& Tansella, 1993). The GHQ-12 has good construct validity; it is negatively associated with good overall wellbeing (Fat, Scholes, Boniface, Mindell \& Stewart-Brown, 2017) and positively with depression (Ludin, Hallgren, Theobald, Hellgren \& Torgen, 2016).

\section{Statistical Analysis}


Data analysis used IBM SPSS ${ }^{\circledR}$ version 23 . Prior to analysis, the normality of the data was examined to determine that assumptions for parametric statistics were met. Exploratory factor analysis determined the latent constructs contained in the 26-item PPWWM after determining suitability for factoring. VARIMAX rotation was used to provide orthogonal factors which are generally easier to interpret when subscales are considered to be independent.

\section{Results}

\section{The Sample}

Of the 479 responses, 67 (14\%) incomplete responses (failed to complete one or more questionnaires) were removed and 10 responses were removed for not meeting the inclusion criteria. In addition, two responses that checked the same option for over $90 \%$ of items were discarded. The final sample of 400 responses gave a power of .99 to detect a small correlation of .2 with $\alpha$ at .05 (Faul et al., 2007). At Time 2, 194 participants (70\%) completed within one week of receiving the email request ( 7 - 14 days after first completion). Apart from the temporal stability analysis, all analyses used results from Time $1(n=400)$. Characteristics of the sample are summarised in Table 2.

[Insert Table 2 about here]

\section{Characteristics of the PPWWM}

Descriptive statistics for the PPWWM are in Table 3. The main sample scores were not normally distributed (Kolmogorov-Smirnov test, $p=0.001$ ): kurtosis $=-.63, p=.009$; skew $=-.27, p=.025$ (two-tailed). However, significance in such a large sample may not indicate severe deviation from normality, so the histogram was inspected. It showed a slightly bimodal distribution with a small peak at 80-85 and a second larger peak at 100-105. 
Bootstrapping was trialled to allow for violation of assumptions but made no difference to any correlations (to 2 decimal places), nor to p-values. Therefore, conventional analyses were conducted.

[Insert Table 3 about here]

The PPWWM correlated strongly with the additional measures as predicted: PPWWM with HSEMS-IT, $r=.88, p<.001$; with SWLS, $r=.50, p<.001$; with GHQ-12, $r$ $=-.31, p<.001$ (all one-tailed). Cronbach's $\alpha=.92$ indicating high internal consistency. This was also evidenced by high or moderate corrected item-total correlations. Only items 19 (.36) and $26(.37)$ had an item-total correlation $<0.4$, and the majority were $>0.5$. The additional measures also exhibited high internal consistency Cronbach's $\alpha$ for HSEMS-IT = .93; SLWS, =.90; GHQ-21 = .91. All PPWWM item responses ranged from 1 to 5 and did not show pronounced floor or ceiling effects, although item 26 had a high mean score with a small standard deviation. The test-retest reliability for the 194 retests at 7 to 14 days was .94 , $p<.001$.

\section{Associations with demographics factors}

Bonferroni corrections were considered but not made due to the small number of comparisons and because they are highly conservative and can fail to identify significant relationships in survey research (Bland and Altman, 1996). Table 4 shows the associations using the eta statistic for nominal data (top) and Kendall's $\Phi_{b}$ for ordinal/interval data (bottom). The same analyses for the HSEMS-IT are given in Table 4 for comparison. Age, type of contract, years since qualification, years worked since qualification and salary were significantly correlated with the PPWWM and the HSEMS-IT. The mean PPWWM scores in each age category are shown in Table 5. In addition, the HSEMS-IT correlated with 
contracted hours. For contract hours, those with non-permanent contracts demonstrated higher workplace satisfaction then permanent workers. For agenda for change salaries, Band 6 (early career) workers showed the highest workplace satisfaction on both measures.

[Insert Table $4 \& 5$ about here]

\section{Exploratory Factor Analysis of the PPWWM}

The PPWWM data were considered compliant with the assumptions for factor analysis (Field, 2018) notwithstanding the minor deviation from normality. An exploratory factor analysis, using Varimax rotation produced six factors with eigenvalue greater than 1.0 explaining $61.2 \%$ of the variance. Loadings of 0.4 (explaining $16 \%$ of variance) and greater were considered meaningful (Stevens, 2012; Costello and Osborne, 2005). All items predominantly loaded onto one of the six factors.

Factor 1 contained nine items about 'professional and organisational satisfaction'. Factor 2 contained six items about 'support and flexibility'. Factor 3 contained four items about a psychological practitioner's 'professional role'. Factor 4 contained two items associated with the appropriateness and impact of the 'physical environment' of the workplace. Factor 5 contained two items relating to 'clinical supervision'. Factor 6 contained three items about 'external personal' support.

Table 6 shows the factors with their loadings and their relationship to the domains and constructs used to generate the items.

Insert Table 6 about here

\section{Discussion}

The PPWWM items derived from the inductive thematic analysis of interviews about workplace wellbeing with psychological practitioners, relevant literature and statistical 
analyses of expert reviews. The themes covered the positive and negative aspects of wellbeing (Maben et al., 2012; Bakker \& Demerouti, 2007; Hobfoll \& Shirom, 2001) and psychological practitioners were readily able to use them as a framework to guide the development of items. Many of the themes used to develop items (Table 1) referenced factors often considered as antecedents of wellbeing rather than part of the experience of wellbeing itself. However, items relating to these factors focussed on feelings about and the experience of these factors. For example, a poor physical environment or poor line-management may be antecedents of poor wellbeing, but how a person feels about their environment and linemanagement are also part of the experience of wellbeing.

The PPWWM scores demonstrated a good range without marked floor or ceiling effects and Cronbach alpha was high. The PPWWM also exhibited very high test-retest reliability of .94. There were strong positive correlations with the HSEMS-IT and the SWLS and a strong negative correlation with GHQ-12, indicative of construct validity. The associations with the SWLS and GHQ-12, although significant, were lower than with the HSEMS-IT. This was expected, as factors other than workplace wellbeing are likely to contribute to life satisfaction and general health. This modest correlation reinforces the need for a workplace-specific measure of wellbeing rather than its proxy measurement through factors such as general psychological distress (anxiety and depression) or satisfaction.

Negative associations were found between the PPWWM and age and the other agerelated variables (years since qualification, years worked since qualification and pay scale). The HSEMS-IT also exhibited a similar pattern of negative associations. These negative associations represented the overall trend and were principally a result of the high levels of wellbeing in the youngest two cohorts. (The rise in wellbeing for the oldest cohort is intriguing, but based on very low numbers). These negative associations contrast with research showing that younger, less experienced cohorts of psychologists exhibit lower 
wellbeing and higher burnout. For example, higher emotional exhaustion and depersonalisation of clients in younger, less experienced psychologists have been extensively reported in the USA (e.g. Dorociak, Patricia, Rupert and Zahniser, 2017; Rupert \& Morgan, 2005) and in Australia (D’Souza et al. 2011; Di Benedetto \& Swadling, 2014). These studies included only practitioner psychologists, but a subgroup analysis of psychologists in the current study also demonstrated a reduction in wellbeing for later cohorts. Since these studies are all cross-sectional, the different age-related trends may reflect country-specific cohort effects rather than a developmental trend. It could, for example, be related to changes in expectations and career prospects of successive cohorts in the UK due to new career structures (Agenda for Change) and funding cuts. There was also an association with type of contract and those on permanent contracts demonstrated lower wellbeing than those on temporary contracts. This was unexpected and requires further exploration.

The PPWWM produced six factors encompassing a range of facets of psychological practitioners' wellbeing (see Table 6). Eight of the items would not meet the criterion that Cousins et al. (2004) adopted for selecting items for the HSEMS-IT (loading of $>0.5$ on the main factor and no other factor loadings within 0.2 ). This would eliminate both items indexing the domain of work control and autonomy which would be subsumed into the professional and organisational satisfaction factor. However, the PPWWM dimensions and items were based on qualitative analysis of professionals' views and several stages of expert professional review. While statistically the work control and autonomy dimension may be explained by the professional and organisational satisfaction factor, removing it would eliminate a dimension with an important functional link to well-being (Mackay, Cousins, Kelly, Lee, \& McCaig, 2004) which could guide interventions to improve wellbeing.

Factor 1, 'Professional and Organisational Satisfaction,' generally referenced the stance towards the organisation and how it developed and permitted professional activities. It 
encompassed items relating to demands and targets and employee control and autonomy, highlighting the importance of these two factors in employee wellbeing (Karasek, 1979). Factor 2, 'Support and Flexibility' referenced colleague and managerial support. It principally encompassed the four items from the 'Personal Support-Lack of Support' domain together with items 3 and 4 from 'Organisational Context' and 'Positive and Negative Job Aspects', respectively. Item 3, about belonging, may have been included due to the supportive nature of a sense of belonging (Baumeister \& Leary, 1995) and item 4, about flexible working, could reflect management support for this. Factor 3 contained the four items about a psychological practitioner's 'professional role', including the valuing of a psychological practitioner and role clarity. Originally the value items had been assigned to 'Positive and Negative Job Aspects' domain and the role clarity items to 'Inter-professional Agents'. However, the factor analysis suggests that feelings about work roles form a single domain. Two specific domains, 'Physical Environment' (Factor 4) and 'Clinical Supervision' (Factor 5) produced well-defined factors. Factor 4 supports studies demonstrating that improving the physical workplace environment can improve staff wellbeing (Christenfeld, Wagner, Pastva \& Acrish, 1989) while Factor 5 reflects the documented importance of clinical supervision (British Psychological Society, 2017; Department of Health, 1993). Family support was reflected in the 'External Support' factor (Factor 6), but this factor had links with Factor 2, 'Support and Flexibility', and encompassed work-life balance. This made sense in that external support hinges in part on work-life balance. Overall the factor highlighted the importance of support outside of work, reinforcing previous research demonstrating the importance of social support for healthcare professionals (Ben-Zur \& Michael, 2007). Future research with other samples of practitioner psychologists is needed to verify this factor structure and determine the position and inclusion of particular items. 
The PPWWM differed from the commonly used HSEMS-IT by capturing dimensions particularly relevant to psychological practitioners such as clinical supervision, organisational culture and climate, organisational engagement, physical environment and external person support----as identified by qualitative research (McLellan, 2018). These dimensions were reflected in the 'Clinical Supervision' and 'Physical Environment' and 'Professional and Organisational Satisfaction' factors of the PPWWM that are absent from the HSEMS-IT (Cousins et al, 2004) and may indicate unique aspects of the experience of wellbeing in psychological practitioners.

\section{Strengths and Limitations}

While the PPWWM reflected a broad range of issues relevant to psychological practitioners, this breadth has the drawback that some factors had a small number of items. Factors with less than three or four items may be unstable and unreliable (Costello and Osborne, 2005). If use of the questionnaire in practice indicates a need for more items in each dimension, then there may be a case for adding items and validating a longer version. Although there was an adequate sample size for the present factor analysis, these conclusions could be strengthened and extended by confirmatory factor analyses in new samples.

The items were based on the view of the target population emerging from a qualitative study and covered the dual aspects of workplace wellbeing. The questionnaire was intentionally brief to encourage completion in surveys of professionals, but given that a six factor emerged rather than the expected four factor structure, more items would have improved factorability.

The sample was large enough to have high statistical power to detect associations. However, a high proportion of respondents were female (81\%) and clinical psychologists 
(73.3\%) and few were from other professions or the youngest and oldest age groups. Although, these proportions reflect the demography of the psychological workforce, the PPWWM needs validation with larger samples and subgroup analyses that allow crossvalidation with sub-samples of psychological wellbeing practitioners, high intensity therapists and cognitive behavioural therapists.

International validation is also important; the disparity between the results for the PPWWM and studies in the USA and Australia has been noted above. Schaufeli and Enzmann (1998) found higher levels of emotional exhaustion and depersonalisation in North American psychotherapists than in European samples. The structure of wellbeing constructs also varies across cultures (Longo, Coyne \& Joseph, 2017). It would also be beneficial to study a non-volunteer sample through an organisational survey. Finally, sensitivity of the measure to detect changes in workplace wellbeing associated with specific events or interventions was not assessed.

\section{Potential Applications and Conclusions}

The HSEMS-IT (HSE, 2004) was named an 'indicator tool' in recognition of the known limitations of structured questionnaires and the observation that no single measure can assess all aspects of work-related stress (Edwards et al., 2008). Similarly, while the PPWWM fills a gap by providing a psychological practitioner-focussed indicator of workplace wellbeing, it could be used alongside system-level enquiry and other measures of wellbeing. The PPWWM holds promise as a brief, yet comprehensive measure with the ability to be incorporated into batteries assessing a wider range of workplace wellbeing indicators.

\section{Key Practitioner Message}


- The Psychological Practitioner Workplace Wellbeing Measure (PPWWM) specifically measures factors relevant to the workplace wellbeing of psychological practitioners.

- The PPWWM is acceptable to psychological practitioners, generating only $14 \%$ incomplete responses even when delivered by internet without personal contact.

- The PPWWM has excellent internal consistency and temporal stability (reliability), good construct validity and a coherent factor structure. 


\section{References}

Bakker, A. B., \& Demerouti, E. (2007). The job demands-resources model: State of the art. Journal of managerial psychology, 22, 309-328. doi: 10.1108/02683940

Baumeister, R. F., \& Leary, M. R. (1995). The need to belong: Desire for interpersonal attachments as a fundamental human motivation. Psychological Bulletin, 117, 497529.

Ben-Zur, H., \& Michael, K. (2007). Burnout, social support, and coping at work among social workers, psychologists, and nurses: The role of challenge/control appraisals. Social Work in Health Care, 45, 63-82. doi: 10.1300/J010v45n04_04

Bland, J. M. \& Altman, D. G. (1996). Measurement error. British Medical Journal, 313, 744. doi: $10.1136 / \mathrm{bmj} .313 .7059 .744$

Boorman, S. (2009). NHS health and well-being: Final report (299039). London: Department of Health.

British Psychological Society (2017). Practice Guidelines (3rd ed.). Leicester: British Psychological Society.

Christenfeld, R., Wagner, J., Pastva, G., Acrish, W.P. (1989). How physical settings affect chronic mental patients. Psychiatric Quarterly, 60, 253-264.

Crawford, E. R., LePine, J. A., \& Rich, B. L. (2010). Linking job demands and resources to employee engagement and burnout: A theoretical extension and meta-analytic test. Journal of Applied Psychology, 95, 834-848. doi:10.1037/a0019364

Costello, A. B., \& Osborne, J. W. (2005). Best practices in exploratory factor analysis: Four recommendations for getting the most from your analysis. Practical Assessment, Research and Evaluation, 10, 1-9. doi: 10.1.1.110.9154 
Cousins, R., Mackay, C. J., Clarke, S. D., Kelly, C., Kelly, P. J., \& McCaig, R. H. (2004). 'Management standards' work-related stress in the UK: Practical development. Work \& Stress, 18, 113-136. doi: 10.1080/02678370410001734322

Cushway, D., \& Tyler, P. A. (1994). Stress and coping in clinical psychologists. Stress and Health, 10, 35-42. doi: 10.1002/smi.2460100107

D’Souza, F., Egan, S. J., \& Rees, C. S. (2011). The relationship between perfectionism, stress and burnout in clinical psychologists. Behaviour Change, 28, 17-28. doi: 10.1375/bech.28.1.17

Dattilio, F. M. (2015). The self-care of psychologists and mental health professionals: A Review and practitioner guide. Australian Psychologist, 50, 393-399. doi: 10.1111/ap.12157

Department of Health (1993). A vision for the future. Report of the Chief Nursing Officer. London: DoH.

DeVellis, R. F. (2017). Scale development: Theory and applications (4 ${ }^{\text {th }}$ ed.). Los Angeles: Sage Publications.

Di Benedetto, M., \& Swadling, M. (2014). Burnout in Australian psychologists: Correlations with work-setting, mindfulness and self-care behaviours. Psychology, Health and Medicine, 19, 705-715. doi: 10.1080/13548506.2013.861602

Diener, E., Emmons, R. A., Larsen, R. J., \& Griffin, S. (1985). The satisfaction with life scale. Journal of Personality Assessment, 49, 71-75. doi: 10.1207/s15327752jpa4901_13

Dimotakis, N., Scott, B. A., \& Koopman, J. (2011). An experience sampling investigation of workplace interactions, affective states, and employee well-being. Journal of Organizational Behavior, 32, 572-588. doi: 10.1002/job.722 
Dorociak, K. E., Rupert, P. A., \& Zahniser, E. (2017). Work life, well-being, and self-care across the professional lifespan of psychologists. Professional Psychology: Research and Practice, 48, 429-437. doi: 10.1037/pro0000160

Dosanjh, N. \& Bhutani, G. (2017). Workforce Wellbeing Survey 2014-2016. Workshop presented at the New Savoy Conference 2017: Psychological Therapies in the NHS, London. Available from https://www.newsavoypartnership.org/2017presentations/dosanjh-gbhutani.pdf

Eaton, J. L., Mohr, D. C., Hodgson, M. J., \& McPhaul, K. M. (2018). Development and validation of the work-related well-being index: Analysis of the federal employee viewpoint survey. Journal of Occupational and Environmental Medicine, 60, 180185. doi: 10.1097/JOM.0000000000001196

Edwards, J. A., Webster, S., Van Laar, D., \& Easton, S. (2008). Psychometric analysis of the UK Health and Safety Executive's Management Standards work-related stress Indicator Tool. Work \& Stress, 22, 96-107. doi: 10.1080/02678370802166599

Fat, L. N., Scholes, S., Boniface, S., Mindell, J., \& Stewart-Brown, S. (2017). Evaluating and establishing national norms for mental wellbeing using the short Warwick-Edinburgh Mental Well-being Scale (SWEMWBS): findings from the Health Survey for England. Quality of Life Research, 26, 1129-1144. doi:10.1007/s11136-016-1454-8

Farber, B. A. (1983). The effects of psychotherapeutic practice upon psychotherapists. Psychotherapy: Theory, Research and Practice, 20, 174-182. doi: 10.1037/h0088488 Faul, F., Erdfelder, E., Lang, A. G., \& Buchner, A. (2007). G* Power 3: A flexible statistical power analysis program for the social, behavioral, and biomedical sciences. Behavior 
research methods, 39, 175-191. Retrieved from

https://link.springer.com/content/pdf/10.3758\%2FBF03193146.pdf

Field, A. (2018). Discovering statistics using IBM SPSS Statistics $\left(5^{\text {th }}\right.$ ed.) London: Sage Publications.

Fisher, C. D. (2010). Happiness at work. International journal of management reviews, 12, 384-412. doi:10.1111/.14682370

Goldberg, D. (1992). General Health Questionnaire (GHQ-12). Windsor: NFER-NELSON

Hall, L. H., Johnson, J., Watt, I., Tsipa, A., \& O’Connor, D. B. (2016). Healthcare staff wellbeing, burnout, and patient safety: A systematic review. PLoS ONE, 11, 1-12. e0159015. doi:10.1371/.0159015

Hankins, M. (2008). The reliability of the twelve-item general health questionnaire (GHQ-12) under realistic assumptions. BioMed Central Public Health, 8, 1-7. doi: $10.1186 / 1471-2458-8-355$

Hardy, G. E., Shapiro, D. A., Haynes, C. E., \& Rick, J. E. (1999). Validation of the General Health Questionnaire-12: Using a sample of employees from England's health care services. Psychological Assessment, 11, 159-165. doi: 1040-3590/99

Health and Safety Executive. (n.d.). Management Standards Analysis Tool. 153 User Manual. Retrieved from https://www.hse.gov.uk/stress/assets/docs/indicatortoolmanual.pdf. (Accessed 17/06/2019).

Health and Safety Executive (HSE). (2004). Management Standards Indicator Tool. Retrieved from https://www.hse.gov.uk/stress/assets/docs/indicatortool.pdf (Accessed 17/06/2019). 
Hobfoll, S. E., \& Shirom, A. (2001). Conservation of resources theory: Applications to stress and management in the workplace. In R. T. Golembiewski (Ed.), Handbook of organizational behavior (pp. 57-80). New York, US: Marcel Dekker.

Johnson, S., Cooper, C., Cartwright, S., Donald, I., Taylor, P., \& Millet, C. (2005). The experience of work-related stress across occupations. Journal of managerial psychology, 20, 178-187. doi: 10.1108/02683940510579803

Karasek, R. A. (1979). Job demands, job decision latitude, and mental strain: Implications for job redesign. Administrative Science Quarterly, 24, 285-307.

Kerr R., McHugh M., \& McCory M. (2009). HSE management standards and stress-related work outcomes. Occupational Medicine, 59, 574-579. doi: 10.1093/occmed/kqp146

Larsen, R.J., Diener, E., \& Emmons, R.A. (1985). An evaluation of subjective well-being measures. Social Indicators Research, 17, 1-18. doi: 10.1007/BF00354108

Lasalvia, A., Bonetto, C., Bertani, M., Bissoli, S., Cristofalo, D., Marrella, G., ... \& Marangon, V. (2009). Influence of perceived organisational factors on job burnout: survey of community mental health staff. The British Journal of Psychiatry, 195, 537544. doi: 10.1192/bjp.bp.108.060871

Linton, M. J., Dieppe, P., \& Medina-Lara, A. (2016). Review of 99 self-report measures for assessing well-being in adults: exploring dimensions of well-being and developments over time. BMJ open, 6, 1-16. doi: 10.1136/bmjopen-2015-010641

Longo, Y., Coyne, I., \& Joseph, S. (2017). The scales of general well-being (SGWB). Personality and Individual Differences, 109, 148-159. doi: 10.1016/j.paid.2017.01.005 
Maben, J., Peccei, R., Adams, M., Robert, G., Richardson, A., Murrells, T., \& Morrow, E. (2012). Exploring the relationship between patients' experiences of care and the influence of staff motivation, affect and wellbeing. Final report. Southampton: NIHR Service Delivery and Organization Programme.

Mackay, C.J., Cousins, R., Kelly, P.J., Lee, S., \& McCaig, R. H. (2004). 'Management

Standards' and work-related stress in the UK: Policy background and science. Work \& Stress, 18, 9-112.

Maslach, C., \& Jackson, S. E. (1981). The measurement of experienced burnout. Journal of Organizational Behavior, 2, 99-113. doi: 10.1002/job.4030020205

Maslach, C., \& Jackson, S.E. (1986). Maslach burnout inventory manual (2nd ed.). Palo Alto, California: Consulting Psychologists Press.

Maslach, C., Jackson, S.E., \& Leiter, M.P. (1996). Maslach Burnout Inventory manual (3 ${ }^{\text {rd }}$ ed.). Palo Alto: Consulting Psychologists Press.

Maslach, C., \& Leiter, M. P. (2016). Understanding the burnout experience: recent research and its implications for psychiatry. World Psychiatry, 15, 103111.doi:10.10022031

McLellan, C. (2018). Wellbeing and burnout in mental health service providers. Part 2; The domains influencing wellbeing in Practitioner Psychologists. Doctoral Thesis. Cardiff University.

National Institute for Health and Clinical Excellence. (2009). Mental wellbeing at work (Public Health Guideline ph22). London. NICE.

New Economics Foundation. (2009). National Accounts of Well-being: Bringing real wealth onto the balance sheet. Retrieved from http://b.3cdn.net/nefoundation/2027fb05fed1554aea_uim6vd4c5.pdf 
O’Donnell, G., Deaton, A., Durand, M., Halpern, D., \& Layard, R. (2014). Wellbeing and Policy: Legatum Institute. Retrieved from https://lif.blob.core.windows.net/ lif/docs/default-source/commission-on-wellbeing-and-policy/commission-onwellbeing-and-policy-report---march-2014-pdf.pdf?sfvrsn=0

Oates, J., Jones, J., \& Drey, N. (2017). Subjective well-being of mental health nurses in the United Kingdom: Results of an online survey. International Journal of Mental Health Nursing, 26, 391-401. doi: 10.1111/inm.12263

Pavot, W. \& Diener, E. (2008). The satisfaction with life scale and the emerging construct of life satisfaction. The Journal of Positive Psychology, 3, 137-152. doi: $10.1080 / 17439760701756946$

Pavot, W., Diener, E., Colvin, C. R., \& Sandvik, E. (1991). Further validation of the satisfaction with life scale: Evidence for the cross-method convergence of well-being measures. Journal of Personality Assessment, 57, 149-161. doi: 10.1207/s15327752jpa5701_17

Picardi, A., Abeni, D., \& Pasquini, P. (2001). Assessing psychological distress in patients with skin diseases: reliability, validity and factor structure of the GHQ-12. Journal of the European Academy of Dermatology and Venereology, 15, 410-417. doi: 10.1046/j.1468-3083.2001.00336.x

Piccinelli, M., Bisoffi, G., Bon, M. G., Cunico, L., \& Tansella, M. (1993). Validity and testretest reliability of the Italian version of the 12-item general health questionnaire in general practice: a comparison between three scoring methods. Comprehensive Psychiatry, 34, 198-205. doi: 10.1016/0010-440X(93)90048-9 
Ruiz, F. J., García-Beltrán, D. M., \& Suárez-Falcón, J. C. (2017). General health questionnaire- 12 validity in Colombia and factorial equivalence between clinical and nonclinical participants. Psychiatry Research, 256, 53-58. doi:

10.1016/j.psychres.2017.06.020

Rupert, P. A., \& Kent, J. S. (2007). Gender and work setting differences in career-sustaining behaviors and burnout among professional psychologists. Professional Psychology: Research and Practice, 38, 88-96. doi: 10.1037/0735-7028.38.1.88

Rupert, P. A., \& Morgan, D. J. (2005). Work setting and burnout among professional psychologists. Professional Psychology: Research and Practice, 36, 544-550. doi: $10.1037 / 0735-7028.36 .5 .544$

Schaufeli, W., \& Enzmann, D. (1998). The burnout companion to study and practice: A critical analysis. Philadelphia: Taylor \& Francis.

Smith, P. L., \& Moss, S. B. (2009). Psychologist impairment: What is it, how can it be prevented, and what can be done to address it? Clinical Psychology: Science and Practice, 16, 1-15. doi: 10.1111/j.1468-2850.2009.01137.x

Steel, C., Macdonald, J., Schröder, T., \& Mellor-Clark, J. (2015). Exhausted but not cynical: burnout in therapists working within Improving Access to Psychological Therapy Services. Journal of Mental Health, 24, 33-37. doi: 10.3109/09638237.2014.971145

Stevens, S. (2014). Five Year Forward View. London: NHS England.

Stevens, J. P. (2012). Applied multivariate statistics for the social sciences. New York: Routledge.

Tinsley, H. E., \& Tinsley, D. J. (1987). Uses of factor analysis in counseling psychology research. Journal of Counseling Psychology, 34, 414. doi: 10.1037/00220167.34.4.414 
Van Laar, D., Edwards, J. A., \& Easton, S. (2007). The work-related quality of life scale for healthcare workers. Journal of advanced nursing, 60, 325-333. doi: 10.1111/j.1365-2648.2007.04409.x

Warr, P. (2011). Work, happiness, and unhappiness. Psychology Press.

Werneke, U., Goldberg, D. P., Yalcin, I., \& Üstün, B. T. (2000). The stability of the factor structure of the General Health Questionnaire. Psychological Medicine, 30, 823-829. doi: $10.1017 / \mathrm{S} 0033291799002287$

Westwood, S., Morison, L., Allt, J., \& Holmes, N. (2017). Predictors of emotional exhaustion, disengagement and burnout among improving access to psychological therapies (IAPT) practitioners. Journal of mental health, 26, 172-179.

doi:10.1080/09638237.2016.1276540 
Table 1

Domains and constructs from McLellan (2018) and in the PPWWM after item and construct review.

\begin{tabular}{|c|c|c|}
\hline $\begin{array}{l}\text { Domains from } \\
\text { McLellan (2018) }\end{array}$ & $\begin{array}{l}14 \text { Constructs from McLellan } \\
\text { (2018) }\end{array}$ & 13 Constructs of PPWWM ${ }^{\mathrm{a}}$ \\
\hline \multirow[t]{4}{*}{ 1. Personal support } & Friends and family & Friends and family \\
\hline & Colleagues & Colleagues \\
\hline & Clinical supervision & Clinical supervision \\
\hline & Professional management ${ }^{b}$ & Line management \\
\hline \multirow{4}{*}{$\begin{array}{l}\text { 2. Organisational } \\
\text { context }\end{array}$} & Targets & Targets \\
\hline & Hopefulness $v s$. hopelessness & Hopefulness vs. hopelessness \\
\hline & Pressure & Deleted \\
\hline & & Added Organisational engagement \\
\hline \multirow{5}{*}{$\begin{array}{l}\text { 3. Positive and } \\
\text { negative job } \\
\text { aspects }\end{array}$} & $\begin{array}{l}\text { Control and autonomy over } \\
\text { work }\end{array}$ & Control and autonomy over work \\
\hline & Feeling valued & Feeling valued \\
\hline & Opportunities to learn & Opportunities to learn \\
\hline & Physical environment & Physical environment \\
\hline & Work/Life balance & Work/Life balance \\
\hline \multirow{2}{*}{$\begin{array}{l}\text { 4. Inter-professional } \\
\text { agents }\end{array}$} & Line-management ${ }^{\mathrm{c}}$ & Merged with professional \\
\hline & Role clarity & $\begin{array}{l}\text { management } \\
\text { Role clarity }\end{array}$ \\
\hline
\end{tabular}

Notes.

${ }^{a}$ Actions from development stages are noted in italics and grey scale. ${ }^{b}$ Professional management is normally by a more senior member of the same profession and encompasses: evaluation of work in relation professional standards for conduct, performance and ethical practice; recommendations for professional development and for further training, etc. The professional manager may sit outside the formal management hierarchy of the organisation. ${ }^{\mathrm{c}}$ Line management may be by a general manager or a member of another profession. It is the formal management system of an organisation responsible for routine aspects of employment: monitoring performance in terms of organisation objectives; employee appraisal; career development; wellbeing; monitoring sickness and fitness to work; annual leave; mandatory training; discipline and capabilities. 
Table 2

Participant demographic Information

\begin{tabular}{|c|c|c|}
\hline Variable & Value & $\mathrm{n}(\%)$ \\
\hline $\begin{array}{l}\text { Primary profession } \\
(\mathrm{N}=400)\end{array}$ & $\begin{array}{l}\text { Clinical psychologist } \\
\text { Psychological wellbeing practitioner } \\
\text { Cognitive behaviour therapist } \\
\text { Counsellor } \\
\text { High intensity therapist } \\
\text { Other }\end{array}$ & $\begin{array}{l}293(73.25) \\
36(9.00) \\
28(7.00) \\
15(3.75) \\
14(3.50) \\
14(3.50)\end{array}$ \\
\hline Contract $(\mathrm{N}=400)$ & $\begin{array}{l}\text { Permanent } \\
\text { Non-permanent/fixed term } \\
\text { Other }\end{array}$ & $\begin{array}{l}363(90.75) \\
31(7.75) \\
6(1.00)\end{array}$ \\
\hline $\begin{array}{l}\text { Years since } \\
\text { professional } \\
\text { qualification }(\mathrm{N}=400)\end{array}$ & $\begin{array}{l}\text { Up to } 5 \text { years } \\
5-15 \text { years } \\
16-25 \text { years } \\
26-35 \text { years } \\
36 \text { years or more }\end{array}$ & $\begin{array}{l}116(29.00) \\
158(39.50) \\
88(22.00) \\
33(8.25) \\
5(1.25)\end{array}$ \\
\hline $\begin{array}{l}\text { Years worked since } \\
\text { professional } \\
\text { qualification }(\mathrm{N}=400)\end{array}$ & $\begin{array}{l}\text { Up to } 5 \text { years } \\
5-15 \text { years } \\
16-25 \text { years } \\
26-35 \text { years } \\
36 \text { years or more }\end{array}$ & $\begin{array}{l}124(31.00) \\
155(38.75) \\
88(22.00) \\
28(7.00) \\
5(1.25)\end{array}$ \\
\hline $\begin{array}{l}\text { Weekly contracted } \\
\text { hours }(\mathrm{N}=400)\end{array}$ & $\begin{array}{l}<7.5 \text { hours } \\
7.5-15 \text { hours } \\
>15 \text { hours }-22.5 \text { hours } \\
>22.5 \text { hours }-30 \text { hours } \\
>30 \text { hours }-37.5 \text { hours } \\
>37.5 \text { hours }\end{array}$ & $\begin{array}{l}4(1.00) \\
14(3.50) \\
55(13.72) \\
78(19.50) \\
223(55.75) \\
26(6.50)\end{array}$ \\
\hline $\begin{array}{l}\text { Organisation type } \\
(\mathrm{N}=400)\end{array}$ & $\begin{array}{l}\text { NHS } \\
\text { Private/ Independent } \\
\text { Third Sector/ Charitable } \\
\text { Equal NHS and non-NHS } \\
\text { Other }\end{array}$ & $\begin{array}{l}354(88.50) \\
24(6.00) \\
10(2.50) \\
3(0.75) \\
9(2.25)\end{array}$ \\
\hline Pay scale $(\mathrm{n}=400)$ & AfC $^{a}$ Band $4(£ 19,409-£ 22,683)$ & $5(1.25)$ \\
\hline
\end{tabular}


AfC Band $5(£ 22,128-£ 28,746)$

$28(7.00)$

AfC Band 6 (£26,565 - £35,577)

$31(7.75)$

AfC Band 7 (£31,696 - £41,787)

$70(17.50)$

AfC Band 8A (£40,428 - £48,514)

$110(27.50)$

AfC Band 8B ( $£ 47,092-£ 58,217)$

$52(13.00)$

AfC Band 8C (£56,665 - £69,168)

$52(13.00)$

AfC Band 8D (£67,247 - £83,258)

$22(5.50)$

AfC Band $9(£ 79,415-£ 100,431)$

$6(1.50)$

Other (non- Agenda for Change salary:

$19(5.25)$

Average £60,263)

Do not wish to disclose

$5(1.25)$

Participant gender

Female

$324(81.00)$

$(\mathrm{N}=400)$

Male

73 (18.25)

Transgender

$1(0.25)$

Do not wish to disclose

$2(0.50)$

Participant age

$18-24$

$5(1.25)$

$(\mathrm{N}=400)$

25-34

$83(20.75)$

$35-44$

$142(35.50)$

$45-54$

$117(29.25)$

$55-64$

$46(11.50)$

$65-74$

$3(0.75)$

Do not wish to disclose

$4(1.00)$

Any long-standing Yes

$47(11.75)$

illness or disability

No

$348(87.00)$

$(\mathrm{N}=400)$

Do not wish to disclose

$5(1.25)$

Note. ${ }^{\text {a }}$ AfC $=$ Agenda for Change Payscale 2017/2018 
Table 3

PPWWM descriptive statistics

\begin{tabular}{lcccccccc}
\hline & N & Range & Min & Max & $M$ & $S D$ & Median & Mode \\
\hline $\begin{array}{l}\text { PPWWM total; } \\
\text { Time 1 }\end{array}$ & 400 & 82 & 47 & 129 & 93.47 & 17.67 & 96 & 101 \\
\hline $\begin{array}{l}\text { PPWWM total; } \\
\text { Time 2 (re-test) }\end{array}$ & 194 & 78 & 51 & 129 & 95.95 & 16.99 & 98 & 104 \\
$\begin{array}{l}\text { Time 1 scores for } \\
\text { re-test subsample }\end{array}$ & 194 & 77 & 50 & 127 & 94.56 & 18.43 & 98 & 98 \\
\hline
\end{tabular}


Table 4

Association of PPWWM and HSEMS-IT scores with nominal (top) and ordinal/interval variables (bottom).

\begin{tabular}{lcccccc}
\hline \multirow{2}{*}{ Variable } & \multicolumn{3}{c}{ PPWWM } & \multicolumn{3}{c}{ HSEMS-IT } \\
\cline { 2 - 7 } & $\eta^{a}$ & $F(d f)$ & $p^{*}$ & $\eta^{a}$ & $F(d f)$ & $p$ \\
\hline Primary profession & .07 & $.37(5,396)$ & .866 & .13 & $1.23(5,396)$ & .272 \\
Type of contract & .12 & $3.07(2,395)$ & $.047^{*}$ & .15 & $4.66(2,399)$ & $.010^{*}$ \\
Type of organisation & .13 & $1.58(4,395)$ & .179 & .14 & $1.94(4,395)$ & .104 \\
Gender & .10 & $2.13(2,395)$ & .120 & .10 & $1.96(3,395)$ & .142 \\
Illness or disability & .05 & $.83(1,393)$ & .363 & .03 & $.36(1,393)$ & .550 \\
\hline
\end{tabular}

\begin{tabular}{lcccc}
\hline \multirow{2}{*}{ Variable } & \multicolumn{2}{c}{ PPWWM } & \multicolumn{2}{c}{ HSEMS-IT } \\
\cline { 2 - 5 } & $\tau_{\mathrm{b}}$ & $p$ & $T_{\mathrm{b}}$ & $p$ \\
\hline Years since professional qualification & -.08 & $.015^{*}$ & -.09 & $.008^{* *}$ \\
Years worked since professional qualification & -.09 & $.010^{*}$ & -.09 & $.006^{* *}$ \\
Number of contracted hours per week & .05 & .085 & .06 & $.047^{*}$ \\
Agenda for change pay scale & -.07 & $.025^{*}$ & -.10 & $.003^{* *}$ \\
Age & -.10 & $.003^{* *}$ & -.08 & $.025^{*}$ \\
\hline Note. ${ }^{\mathrm{a}} \eta=\mathrm{Eta} \quad{ }^{*} \mathrm{p}<.05 ; * * \mathrm{p}<.01$ & & & &
\end{tabular}


Table 5

Age and PPWWM scores

\begin{tabular}{ccc}
\hline Age & PPWWM Mean (SD) & N \\
$18-24$ & $114.8(10.4)$ & 5 \\
$25-34$ & $98.7(15.8)$ & 83 \\
$35-44$ & $90.9(18.3)$ & 142 \\
$45-54$ & $92.9(17.6)$ & 117 \\
$55-64$ & $90.6(16.0)$ & 46 \\
$65-74$ & $99.0(22.7)$ & 3 \\
Total & $93.5(17.6)$ & 396 \\
\hline
\end{tabular}


Table 6

Factor structure and item loadings for the six-factor solution of the PPWWM

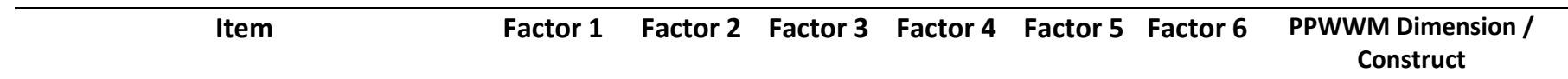

Factor 1: Professional and organisational satisfaction

7. I feel I can balance less fulfilling aspects of my job with more enjoyable aspects

8. I cannot see how the service/ organisation in which I work can ever be delivered effectively

10. I am enabled to manage and organise my workload and diary

12. I feel confident the service/ organisation in which I work can adapt to meet future service demands

18. I do not feel included in service/ organisational decisions that affect me

21. My continuing professional development needs are supported

22. I am encouraged and supported to develop my skill-set and knowledge

23. I am expected to reach unrealistic or unattainable targets

25. I feel service/ organisational targets are meaningful

.477

.066

.120

.048

.446

.229

.178

.176

$$
.168
$$

.086

.152

.251 context/Organisational hopefulness-hopelessness

Positive and negative job aspects/Work control and autonomy

Organisational context/Organisational hopefulness-hopelessness

$$
\begin{gathered}
\text { Organisational } \\
\text { context/Organisational } \\
\text { engagement }
\end{gathered}
$$

Positive and negative job aspects/Opportunities to learn

Positive and negative job aspects/Opportunities to learn

$$
\begin{gathered}
\text { Organisational } \\
\text { context/Organisational } \\
\text { targets }
\end{gathered}
$$

Organisational context/Organisational targets

Factor 2: Support and flexibility

2. I feel I can seek support from my colleagues

$-.020$

.580

.210

.148

.154

.367

Personal support-lack of

3. I feel a sense of belonging to the service/ organisation in .357

$$
.527
$$

.127

.029

which I work

4. Flexible working arrangements

are supported in my

support/Colleagues

Organisational context/Organisational engagement

Positive and negative job aspects /Work-life balance 
5. I feel supported by my linemanager to take positive risks without fear of reproach

6. I work in an environment where my colleagues are caring and supportive towards each other

20. My line-manager is approachable and responsive
Personal support-lack of support/Colleagues

$\begin{array}{lllllll}-.017 & .568 & .451 & .235 & .154 & .216\end{array}$

.259

.644

.117

.113

.239

.224

Personal support-lack of support/Management

Factor 3: Professional Role

11. I am clear of my role in relation to other professionals .263 .035 .680 .034 .264

$-.015$ Inter-professional with whom I work

14. My colleagues have realistic expectations of my professional .251 .124 .540 .365 .180

Inter-professional role professional contribution aspects /Feeling valued

26. My specific skills as a psychological practitioner add value to the team/ service/ organisation

15. The physical environment and facilities in my workplace enable me to work efficiently and effectively

24. The physical environment and/ or facilities in my workplace adversely affect my workplace wellbeing

$\begin{array}{llllll}.224 & .119 \quad & .643 & -.124 & -.017 \quad .115\end{array}$

Factor 4: Physical Environment

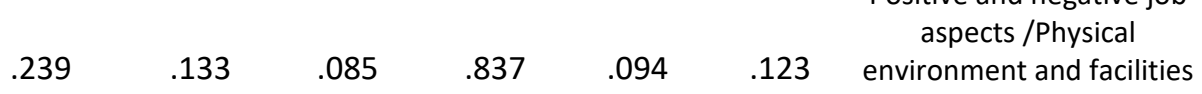

Positive and negative job aspects /Feeling valued

\begin{tabular}{|c|c|c|c|c|c|c|c|}
\hline \multicolumn{8}{|c|}{ Factor 5: Clinical Supervision } \\
\hline $\begin{array}{l}\text { 9. The clinical supervision I } \\
\text { receive is containing and safe }\end{array}$ & .164 & .195 & .083 & .060 & .876 & .063 & $\begin{array}{c}\text { Personal support-lack of } \\
\text { support/Clinical supervision }\end{array}$ \\
\hline $\begin{array}{l}\text { 13. Clinical supervision meets my } \\
\text { support needs }\end{array}$ & .183 & .182 & .153 & .130 & .864 & .157 & $\begin{array}{c}\text { Personal support-lack of } \\
\text { support/Clinical supervision }\end{array}$ \\
\hline
\end{tabular}

Factor 6: External Personal

1. I do not feel there is always someone there for me when I need personal support
Positive and negative job aspects /Physical environment and facilities 
17. I have a good work/ life balance

19. The personal support I

receive from family and/or friends meets my needs
Positive and negative job aspects /Work-life balance

Personal support-lack of .096 .061 .135 .004 .133 .773 


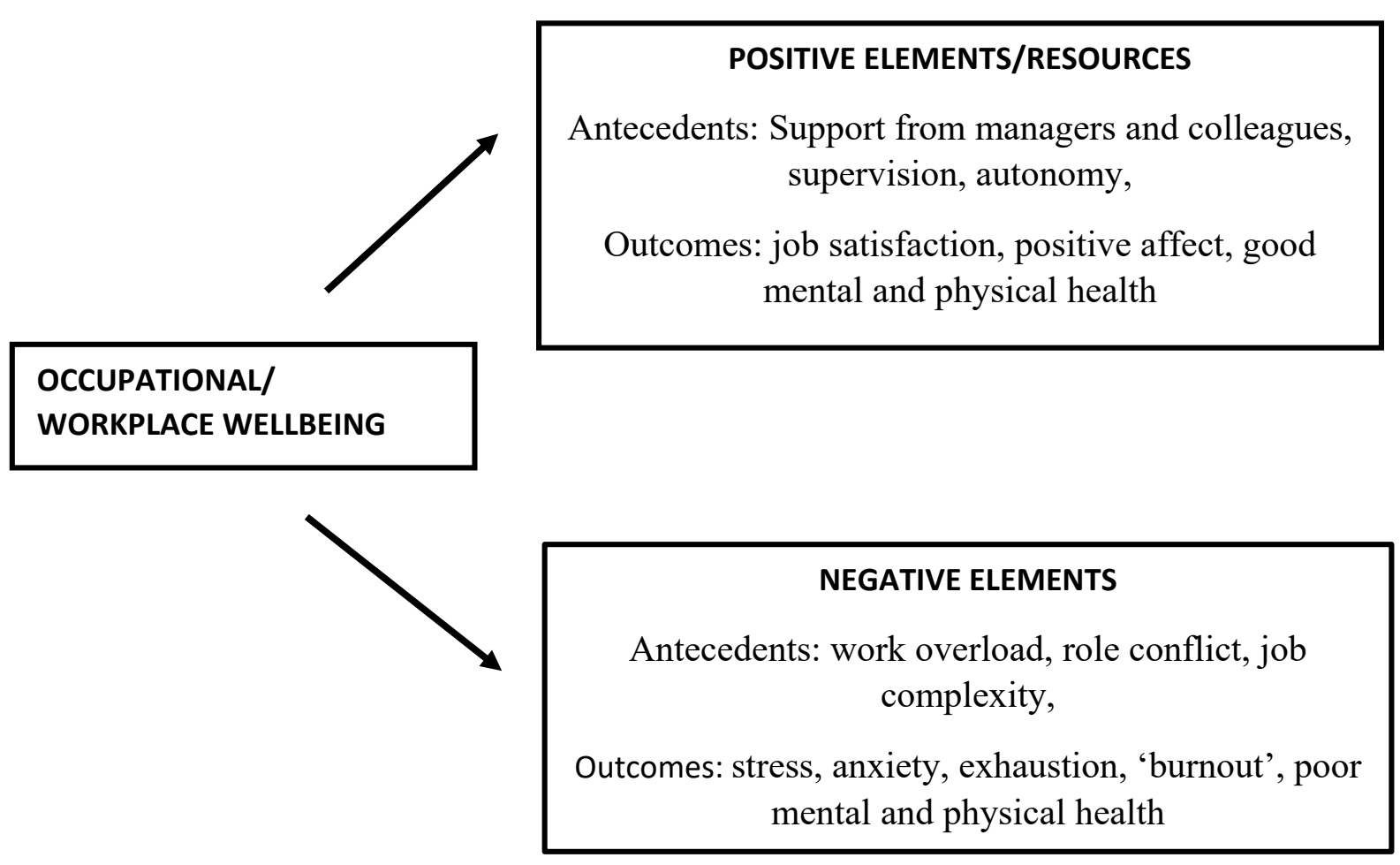

Figure . Elements of occupational wellbeing (After: Maben et al., 2012; Bakker \& Demerouti, 2007; Hobfoll \& Shirom, 2001). 